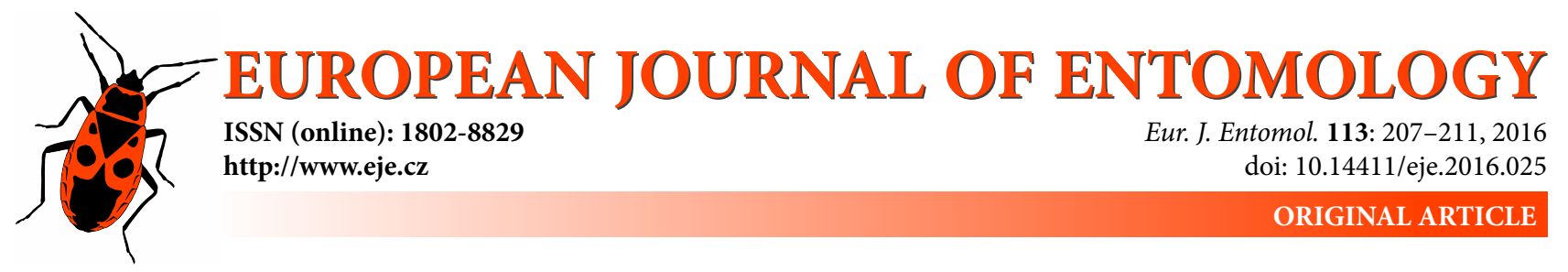

\title{
Size- and context-dependent nest-staying behaviour of males of the Japanese dung beetle, Copris acutidens (Coleoptera: Scarabaeidae)
}

\author{
MAYUMI AKAMINE \\ Department of Forest Science and Resources, College of Bioresource Sciences, Nihon University, 1866 Kameino, Fujisawa, \\ Kanagawa 252-0880, Japan; e-mail: akamayum@gmail.com
}

Key words. Coleoptera, Scarabaeidae, Copris acutidens, reproductive behaviour, male dimorphism, subsocial Scarabaeinae, post-copulatory processes, paternal provisioning

\begin{abstract}
Male dimorphism in insects is often accompanied by alternative mating tactics, which may, together with morphological traits, determine fitness of the different male morphs. Fitness consequences of male head horn size, male-male competition and male nest-staying behaviour were experimentally assessed in Copris acutidens, in which major and minor males can co-occur in nests. Possible differences in their reproductive behaviour and breeding success were assayed in a breeding experiment, in which females were paired with one major male, one minor male, or a pair of major and minor males. The advantage of major males staying in a nest along with a rival male is that major males are reproductively more successful than minor males in this species. The weight of dung transported into nests was significantly less in rearing containers containing two males than in those with a single male of either morph, although it did not differ between major and minor males when kept alone. The results indicate that the presence of a rival male negatively affects male provisioning due to interference from rival males. In contrast, in the present study, an increased incidence of male nest-staying behaviour was recorded in the two- male and one minor male treatment than in the one major male treatment. These results indicate that because of the risk of sperm competition, major males stay longer in nests if a rival male is present. Furthermore, minor males (which are subject to a higher risk of sperm competition) stay longer than major males in nests without a rival male. In other words, the present study revealed an alternative behaviour during the post-copulatory stage associated with horn dimorphism and the presence or absence of a rival male.
\end{abstract}

\section{INTRODUCTION}

Insects often exhibit extreme morphology (Emlen \& Nijhout, 2000). The exaggerated traits are commonly sexually dimorphic and are often expressed in males. Beetle horns are among the most well-known examples of such traits and numerous studies have revealed the competitive advantage associated with the possession of large horns (Eberhard, 1979; Siva-Jothy, 1987; Rasmussen, 1994; Emlen, 1997; Moczek \& Emlen, 2000; Pomfret \& Knell, 2006). Most of these studies indicate that horns are used as weapons in male-male contests (Eberhard, 1980). Males larger than a critical body size develop disproportionally long horns (major males), whereas smaller males develop only rudimentary horns (minor males). In many taxa, minor males adopt alternative tactics to avoid direct competition with large males and gain access to females (Eberhard, 1982; Emlen, 1997; Siva-Jothy, 1987).

On the other hand, there is little information on postcopulatory behaviour in the context of sexual selection (Cook, 1990; Okada \& Hasegawa, 2005; Trillo, 2008; Halffter \& Favila, pers. comm.), although this informa- tion is needed for a comprehensive understanding of the evolution of sexually selected traits (Trillo, 2008). In the dung beetle genus Copris, male horn morphology has been investigated in only a few species (Eberhard \& Gutiérrez, 1991; Sugiura et al., 2007). However, the behaviour associated with dimorphism and the adaptive aspects of these morphological features, except for a single field observation of combat using horns in C. lunaris (Rommel, 1967), is poorly documented.

When both sexes construct nests, provisioning of food for the progeny by major and minor males can differ. In dung beetles, major males provide more food in Onthophagus, whereas both morphs contribute similarly in Phanaeus (Cook, 1988; Hunt \& Simmons, 1998; Rasmussen, 1994). Even female parental care in both genera is generally restricted to brood mass construction (Halffter \& Edmonds, 1982). On the other hand, females of the genus Copris are considered to be subsocial in terms of their nesting behaviour. They repair fractured brood balls, prevent larval death by desiccation and fungal infection, and repulse predators and parasites (Halffter et al., 1996). The male cooperates 

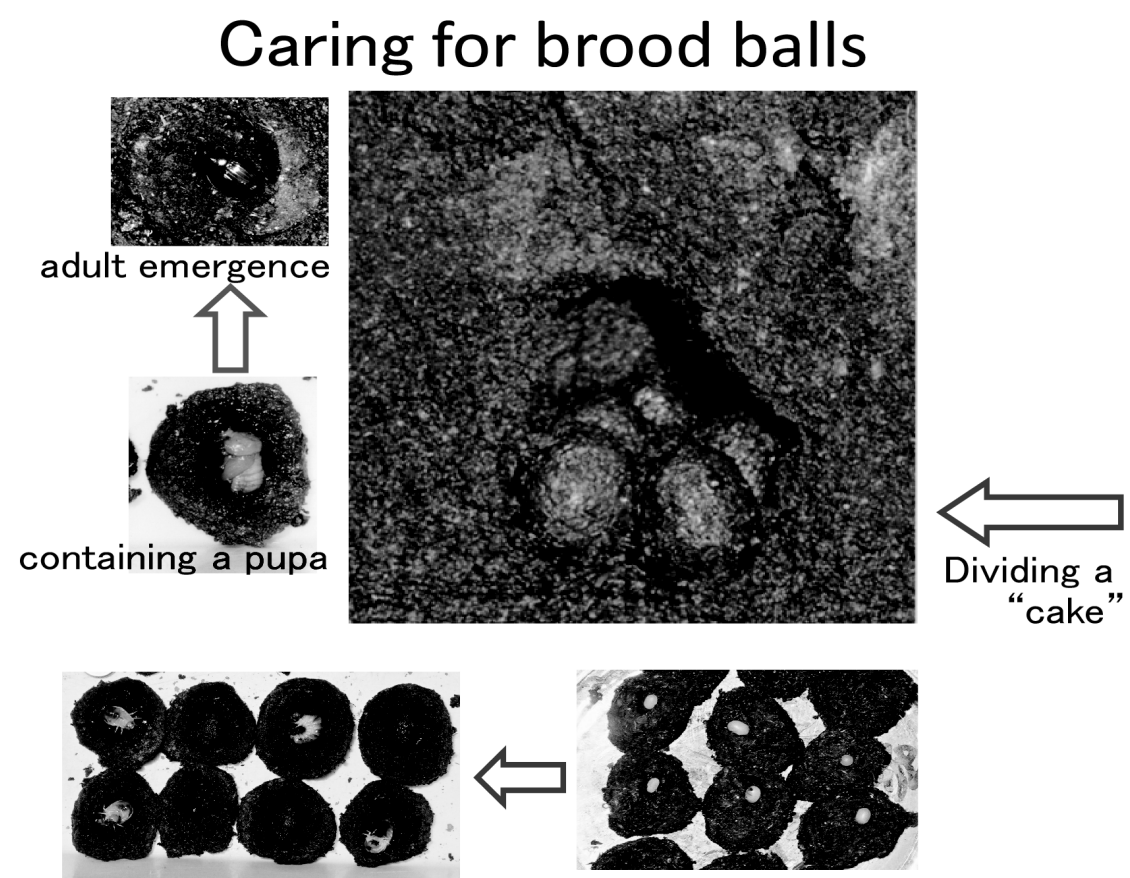

1. pairing only

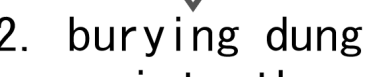
into the nest

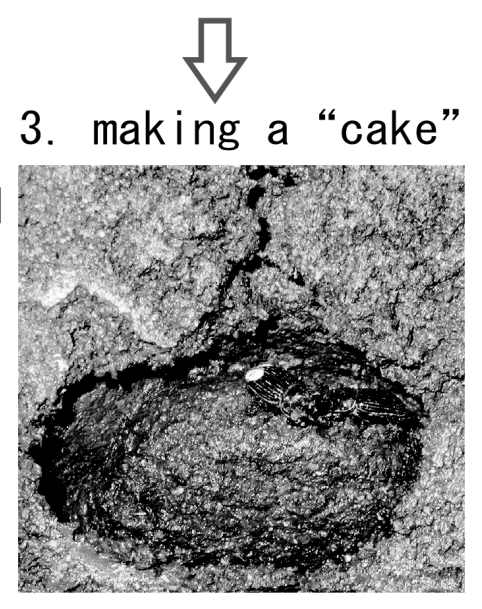

\section{5. containing a larva}

4. containing an egg

Fig. 1. General nesting behaviour in the genus Copris. Most females make a dung mass (a "cake") from dung carried into the nest. After approximately a week the female divides the "cake" into several brood balls and lays an egg in each ball. The female then takes care of the larvae until they emerge as adults.

with the female by providing food for the progeny but does not participate in brood-ball care. However, the male may stay in the nest for the first month, although some variation exists between species (Halffter \& Edmonds, 1982). This behaviour may be considered as post copulation mate guarding.

The aim of the present study was to experimentally assess the fitness consequences of male head horn size, male-male competition and male nest-staying behaviour in Copris acutidens Motschulsky. Differences in the reproductive behaviour and breeding success of both male morphs were determined in a breeding experiment in which a rival male was absent or present.

\section{MATERIALS AND METHODS}

\section{Model species}

Copris acutidens is a common dung beetle species with obvious sexual dimorphism and dimorphism in the horn size of the males (Masumoto, 1967). Allometric analysis in this species revealed that the horn dimorphism follows a discontinuous pattern, such that the males can be classified as either a major or minor morph (Akamine, 2016). Females care for the brood balls until the progeny emerge (Fig. 1; Mizuta, 1959; Halffter \& Edmonds, 1982; Imamori, 1985). Recent observations of C. acutidens in the field indicate that some males stay in the nest for more than a month or until the larvae reach the last instar (Akamine \& Sato, 2011), although males are also reported leaving nests once the female has completed making a dung cake (Mizuta, 1959; Fig. 1) or laying eggs (Imamori, 1985; Fig. 1).

\section{Experiment on reproductive behaviour}

To determine the differences in nest-staying behaviour of major and minor males and the effect of the presence of a rival male on this behaviour, an experiment was conducted using beetles collected from April to June in 2002 on the north side of Mt.
Takamado in Nara city $\left(34^{\circ} 67^{\prime} \mathrm{N}, 135^{\circ} 86^{\prime} \mathrm{E}\right)$. After collection, head horn length and prothoracic width of 79 male beetles were measured and analyzed using the models of Kotiaho \& Tomkins (2001). The first model tests if the relationship between horn length and prothoracic width can be expressed as a simple allometric relationship:

$\ln (Y)=\alpha_{0}+\alpha_{1} \ln (X)+\alpha_{2} \ln (X)^{2}+\varepsilon(1)$

in which $Y$ is horn length; $X$ prothoracic width; $\alpha_{1}$ the regression coefficient and $\varepsilon \sim N\left(0, \mathrm{~s}^{2}\right)$ the residual error. Values of $\alpha_{2}$ that differ significantly from zero indicate a more complex relationship. A further analysis was carried out to determine if the relationship between horn length and prothoracic width, as a measure of body size, is piecewise linear:

$\mathrm{X}=\beta_{0}+\beta_{1} \mathrm{Y}+\beta_{2}\left(\mathrm{Y}-\mathrm{Y}_{0}\right) \mathrm{D}+\beta_{3} \mathrm{D}+\varepsilon(2)$

in which $\mathrm{Y}_{0}$ is the threshold or switch point value; $\mathrm{D}=0$ if $\mathrm{Y}<\mathrm{Y}_{0}$ or otherwise $\mathrm{D}=1$, and $\beta_{1}$ the regression coefficient. The optimal value of $Y_{0}$ was identified to give the maximum value of adjusted $\mathrm{R}^{2}$ calculated using SPSS Statistics version 19 (IBM, Japan). In $\mathrm{Eq}(2)$, if $\beta_{3}$ is significantly different from zero using the optimal switch point value, then the dimorphism is judged as discontinuous at $\mathrm{Y}_{0}$. If $\beta_{3}$ is not significantly different from zero, the slope parameter $\beta_{2}$ identifies a continuous dimorphic pattern if the value of $\beta_{2}$ is significantly different from zero. Based on results from $\mathrm{Eq}(2)$, males were categorized as either a major or minor morph based on the estimated threshold value of the dimorphic pattern.

Three experimental groups were compared: 20 rearing containers each containing two males (one minor and one major male) and a randomly selected female, 10 containers containing only one major male and a randomly selected female and 12 containers containing one minor male and a randomly selected female. The prothoracic widths were the same for four male pairs.

All containers $(11 \times 16 \times 15 \mathrm{~cm})$ were around two-thirds full of soil with $50 \mathrm{~g}$ of deer dung and were placed on the floor of the forest on the campus of Nara Women's University, Nara City $\left(34.68^{\circ} \mathrm{N}, 135.82^{\circ} \mathrm{E}\right)$. Females constructed nests in all the rear- 


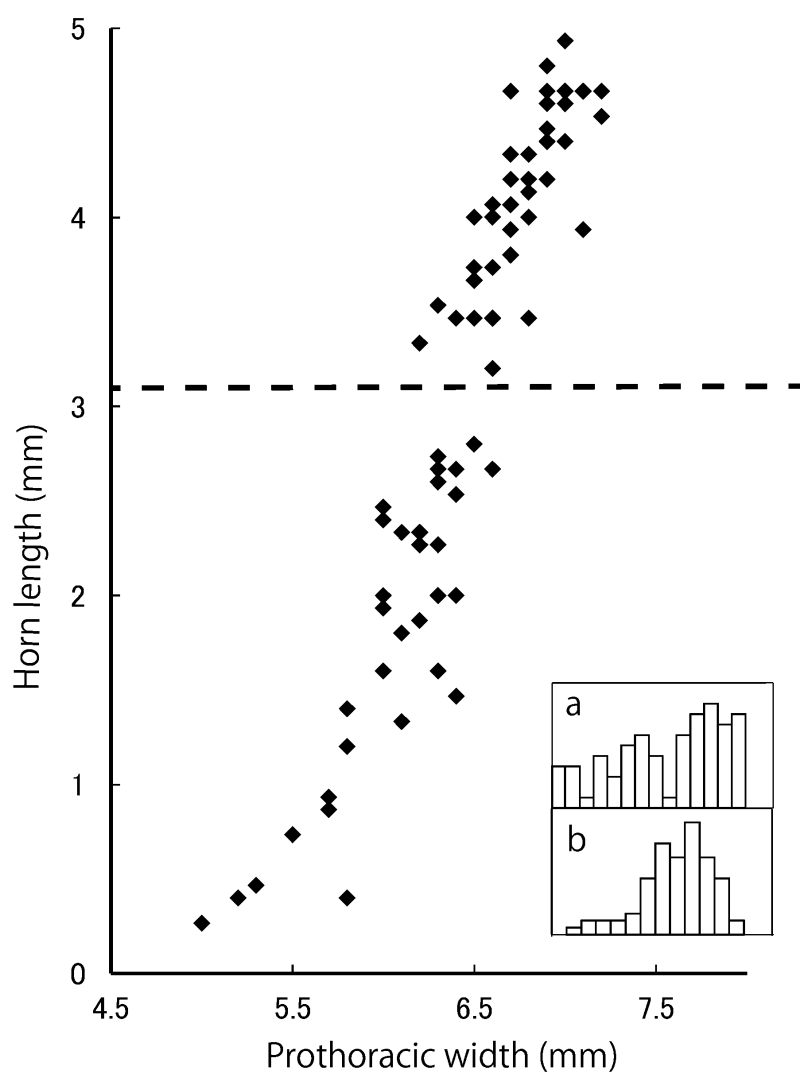

Fig. 2. The scaling relationships between horn length and body size in male $C$. acutidens. a - frequency distribution of horn length b - frequency distribution of prothoracic width as an indicator of body size. Broken line indicates the horn length threshold value (3.1 mm).

ing containers, and there were no differences in the body size of females in the three groups of containers (Kruskal-Wallis test, $p$ $>0.05$ ).

The following nesting index was used to assess the reproductive and nesting behaviour: 1 - pairing only; 2 - burying dung in a nest; 3 - making a dung cake; 4 - caring for a brood ball containing an egg; 5 - caring for a brood ball containing a developing larva (Fig. 1). After 12 days, the nesting index, the presence or absence of a major and/or minor male in the nest, and the weight of dung transported into nests based on either the weight of dung cake and/or brood balls (Fig. 1) were recorded.

\section{RESULTS}

The pattern of the scaling relationships between horn length and male prothoracic width was discontinuous with the horn length threshold value in Eq (2) estimated at 3.1 mm (Fig. 2). Coefficient $\alpha_{2}$ in Eq (1) was significantly different from zero $\left(\alpha_{2}=-13.5 \pm 3.05, \mathrm{t}=-4.4, \mathrm{p}<0.01\right)$. Coefficient $\beta_{3}$ in $\mathrm{Eq}(2)$ was also significantly different from zero $\left(\beta_{3}=-0.21 \pm 0.05, \mathrm{t}=-4.5, \mathrm{p}<0.01\right)$.

In 15 out of 20 containers with pairs of males, one of the males was in the nest with the female. In two of the remaining five containers both males were in the nest and in the remaining three containers no males were in the nest. More major than minor males stayed in the nest with females (Fig. 3, Sign-test, one-sided test, $\mathrm{p}=0.02$ ). For three out of the four male pairs with the same prothoracic width, the major male was in the nest (open symbols in Fig. 3), and in the remaining pair, neither of the males was in the nest (not

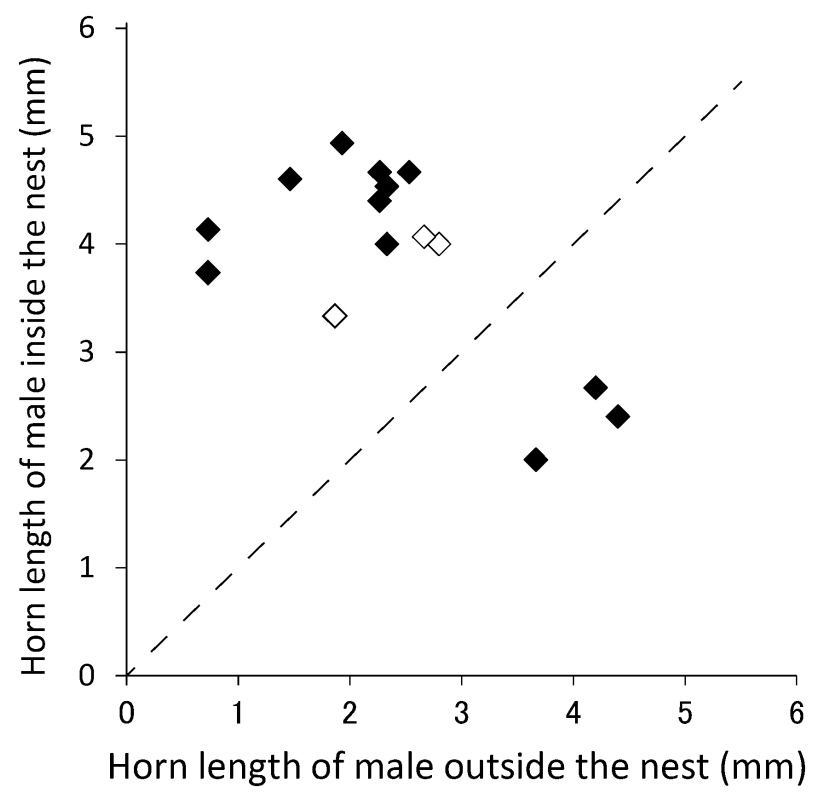

Fig. 3. Relationship between the horn length of males inside and outside the nest in 15 out of 20 containers containing two males. Dashed line indicates equal horn length in both males. Open symbols indicate combinations of males with the same prothoracic width.

shown in Fig. 3). On the other hand, in the 10 containers each with one major male, only three major males were in the nest with the female. The proportion of males in nests was significantly higher in the two-male and one minor male treatments than the one major male treatment (Fig. 4, Fisher's exact test, $\mathrm{p}<0.01$; Shaffer's multiple comparison test: one major male vs. two males, $\mathrm{p}<0.01$; one major male vs. one minor male, $\mathrm{p}=0.03$; one minor male vs. two males, $\mathrm{p}>0.05$ ). Nesting behaviour did not differ significantly among the three groups (Table 1, Fisher's exact test, $\mathrm{p}>0.05)$. Finally, the weight of dung transported into the nest was significantly lower when there were two males in a nest (Fig. 4, Kruskal-Wallis test, $p=0.02$; Tukey-Welsch multiple comparison test, one minor male vs. two males, $\mathrm{p}$ $<0.05$; one major male vs. two males, $\mathrm{p}<0.05$; one major male vs. one minor male, $\mathrm{p}>0.05$ ).

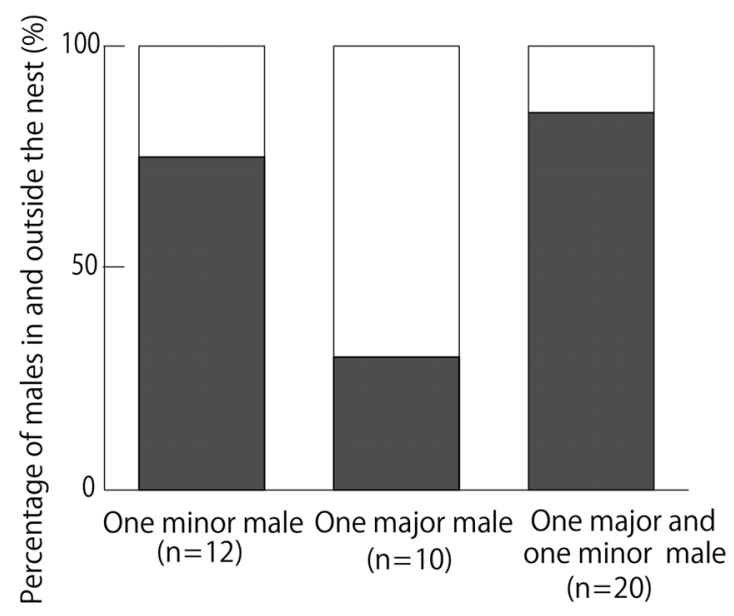

Fig. 4. The percentage of males in and outside the nest in the different pairing conditions. Grey and white bars show the proportion of males in and outside the nest, respectively. 


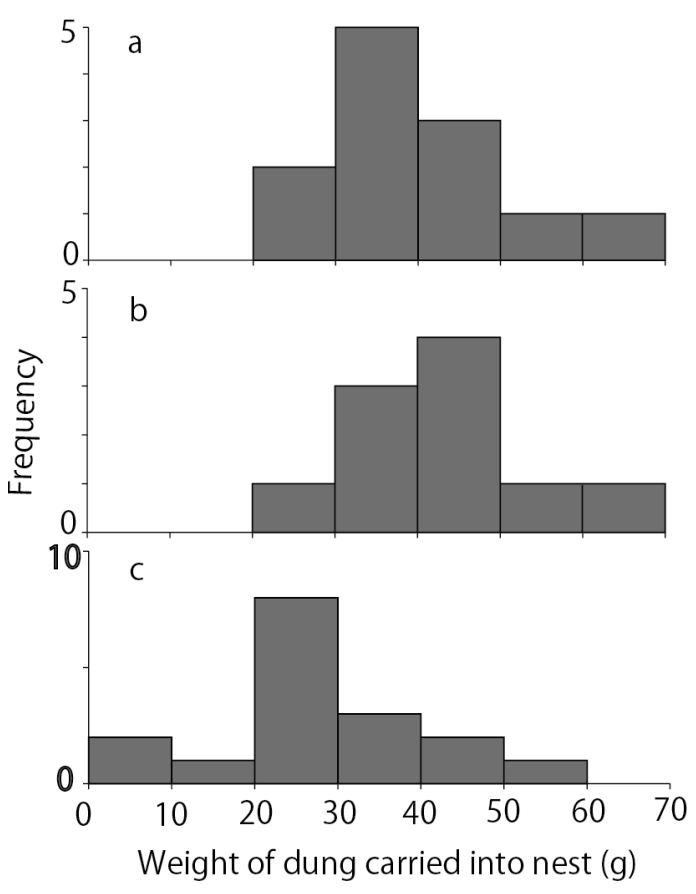

Fig. 5. Histogram showing the weight of dung carried into nests in the different treatments; $a$ - one minor male; $b$ - one major male; $\mathrm{c}$ - two males, one major and one minor male.

\section{DISCUSSION}

Many studies reveal the competitive advantages associated with the possession of exaggerated traits such as the ability of major males to win male-male combats and gain access to females (Eberhard, 1979; Siva-Jothy, 1987; Rasmussen, 1994; Emlen, 1997; Moczek \& Emlen, 2000; Pomfret \& Knell, 2006). In Scarabaeinae, however, paternity may be far from certain: females copulate with several males because, especially in Copris and Phanaeus, copulations are a prerequisite for oocyte maturation (Halffter, 1997). Males can ensure paternity by staying in the nest until the eggs are laid (Halffter, 1997). Furthermore, the last male to copulate with the female has sperm priority as the spermatozoids of the most recent copulation are first expelled from the spermatheca (Halffter, 1997). The present study is based on the assumption that males that stay in the nest with females have a higher probability of being reproductively successful. The head horn in Copris species may be used in combat with other males as in other horned beetles and hence largely determine the reproductive success of a given male. This study did not reveal whether the head horn is used in male-male conflicts in C. acutidens and there is only a single field observation of combat between males of C. lunaris using horns (Rommel, 1967). These uncertainties notwithstanding, as expected major males usually expelled minor males from a nest. However, major and minor males occasionally co-occurred in a nest and sometimes it was the minor male that stayed in the nest, which indicates that in this species additional factors may affect male behaviour.

This study revealed differences in behaviour in the postcopulatory period associated with horn dimorphism and the presence or absence of a rival male. A greater frequency of
Table 1. The reproductive and nesting activities recorded in each treatment: 1 - pairing only; 2 - burying dung in the nest; 3 - making a dung cake from the provisioned dung; 4 - caring for the brood ball each containing an egg; 5 - caring for the brood ball each containing a developing larva.

\begin{tabular}{cccc}
\hline $\begin{array}{c}\text { Nesting } \\
\text { processes }\end{array}$ & One minor male One major male & $\begin{array}{c}\text { One major and } \\
\text { one minor male }\end{array}$ \\
\hline 1 & 0 & 0 & 0 \\
2 & 0 & 0 & 3 \\
3 & 6 & 6 & 6 \\
4 & 6 & 4 & 11 \\
5 & 0 & 0 & 0 \\
\hline Total number & 12 & 10 & 20 \\
\hline
\end{tabular}

male nest-staying was recorded in the two-male and one minor male treatment than in one major male treatment, although the reproductive behaviour in the three groups did not differ. Sperm-competition theory predicts that male expenditure on the ejaculate should increase with risk of sperm competition (Parker, 1997), which assumes a tradeoff between the investment in the ejaculate and other reproductive activities (Simmons et al., 1999). According to this theory, major males should stay longer in nests in the presence of a rival male due to the increased risk of sperm competition. Furthermore, minor males (which are subject to higher risk of sperm competition) might stay longer in nests than major males in the absence of a rival male. The results of this experiment are supportive of both these predictions, although they do not decisively demonstrate that male nest-staying behaviour is mate guarding. Brood balls with a developing larva were not recorded in nests because the experiment was conducted only for 12 days. Presence of a rival male affected the amount of dung in the nest. Less dung was transported into nests where there were two males, although the amount did not differ between major and minor males when kept alone. This indicates that provisioning of nests by males was restricted due interference between rival males but that both male morphs were equally good at provisioning. Unlike in this study, major males of Onthophagus taurus provision their nests with the same amount of dung, irrespective of whether a rival male is present or not, and major O. taurus males provision their nests with more dung than minor males (Hunt \& Simmons, 1998). On the other hand, no difference in the average quantity and rate of dung provision is reported for the major and minor males of Phanaeus difformis (Rasmussen, 1994). These disparate results could be due to differences in the breeding biology of Copris and Phanaeus on the one hand and Onthophagus on the other hand (Knell, 2011). Male Copris and Phanaeus are characterized by low fecundity and high investment per offspring. It is therefore possible that the costs of allowing another male to mate with a female shortly before oviposition are high compared to Onthophagus and, as a result, male contribution to nesting behaviour in Copris may be reduced in the presence of a rival male unlike in Onthophagus. This pattern might be common among taxa with highly evolved nidification such as Copris and Phanaeus (Halffter \& Edmonds, 1982). 
Last but not least, field studies of $C$. acutidens reveal that minor males tend to emerge earlier than major males (Akamine, unpubl.). It is also known that, in the carrion roller beetle, Canthon cyanellus cyanellus, when a male pairs with a previously mated female, the paternity of the last male to mate is significantly higher for previously mated than for virgin males (reviewed in Halffter \& Favila, pers. comm.). In short, if minor males of $C$. $a c u$ tidens emerge early in the season to avoid major males, they can mate with females before major males and employ the strategy of provisioning with the same amount of dung as major males, and then switching to an alternative behaviour associated with dimorphism, i.e. stay longer in the nests than major males in the absence of a rival male to ensure paternity. The combination of these two strategies may compensate for their reduced access to females as a result of their inferior fighting abilities (Okada \& Hasegawa, 2005; Trillo, 2008).

ACKNOWLEDGMENTS. I am grateful to G. Halffter and two other reviewers for providing helpful advice. This study was conducted as a part of my thesis for a Master of Science degree at Nara Women's University.

\section{REFERENCES}

AKamine M. 2016: Dimorphism of both head and prothoracic horn morphologies in male Copris acutidens (Coleoptera, Scarabaoidea). - Entomol. Sci. 19: 82-85.

Akamine M. \& Sato H. 2011: Nesting behavior in Copris acutidens, role of male. - Saikaku Tshushin 22: 9-11 [in Japanese].

Cook D.F. 1988: Sexual selection in dung beetles. II. Female fecundity as an estimate of male reproductive success in relation to horn size, and alternative reproductive strategies in Onthophagus binodis (Coleoptera: Scarabaeidae). — Aust. J. Zool. 36: 521-532.

CooK D.F. 1990: Differences in courtship, mating and postcopulatory behaviour between male morphs of the dung beetle Onthophagus binodis Thunberg (Coleoptera: Scarabaeidae). - Anim. Behav. 40: 428-436.

EBerhard W.G. 1979: The function of horns in Podischnus agenor (Dynastinae) and other beetles. In Blum M.S. \& Blum N.A. (eds): Sexual Selection and Reproductive Competition in Insects. Academic Press, London, pp. 231-258.

Eberhard W.G. 1980: Horned beetles. - Sci. Am. 242: 166-182.

EBERHARD W.G. 1982: Beetle horn dimorphism: making the best of a bad lot. - Am. Nat. 119: 420-426.

Eberhard W.G. \& Gutiérrez E.E. 1991: Male dimorphisms in beetles and earwigs and the question of developmental constrains. - Evolution 45: 18-28.

EgGERT A.-K. \& MülLER J.K. 1997: Biparental care and social evolution in burying beetles: lessons from the larder. In Choe J.C. \& Crespi B.J. (eds): The Evolution of Social Behavior in Insects and Arachnids. Cambridge University Press, Cambridge, pp. 216-236.

EMLEN D.J. 1997: Alternative reproductive tactics and maledimorphism in the horned beetle Onthophagus acuminatus (Coleoptera, Scarabaeoidea). - Behav. Ecol. Sociobiol. 41: 335-341.

EMLEN D.J. \& NiJhout H.F. 2000: The development and evolution of exaggerated morphologies in insects. - Annu. Rev. Entomol. 45: 661-708.
HALFfter G. 1997: Subsocial behavior in Scarabaeinae beetles. In Choe J.C. \& Crespi B.J. (eds): The Evolution of Social Behavior in Insects and Arachnids. Cambridge University Press, Cambridge, pp. 237-259.

Halffter G. \& Edmonds W.D. 1982: The Nesting Behavior of Dung Beetles (Scarabaeidae): An Ecological and Evolutive Approach. Institute de Ecologia, Mexico, 176 pp.

Halffter G., Huerta C. \& Lopez-Portillo J. 1996: Parental care and offspring survival in Copris incertus Say, a sub-social beetle. - Anim. Behav. 52: 133-139.

Hunt J. \& Simmons L.W. 1998: Patterns of parental provisioning covary with male morphology in a horned beetles (Onthophagus taurus) (Coleoptera: Scarabaeidae). - Behav. Ecol. Sociobiol. 42: 447-451.

IMAMORI M. 1985: Dung Beetle; Secret of Chamber. Heibonsya, Tokyo, 44 pp. [in Japanese].

KNELL R.J. 2011: Male contest competition and the evolution of weapon. In Simmons L.W. \& Ridsdill-Smith T.J. (eds): Ecology and Evolution of Dung Beetles. Wiley-Blacwell, Oxford, pp. 47-65.

KотіAно J.S. \& Tomkins J.L. 2001: The discrimination of alternative male morphologies. - Behav. Ecol. 12: 553-557.

Masumото K. 1967: On the Scarabaeidae of Japan (Dung Beetle). - Nature Insects 2: 31-35 [in Japanese].

Mizuta K. 1959: The nests of dung beetles. In Iwata K. et al. (eds): Life Histories of Japanese Insects. Vol. 4, Beetles. Kodansya, Tokyo, pp. 297-316 [in Japanese].

MoczeK A.P. \& EmLen D.J. 2000: Male horn dimorphism in the scarab beetle, Onthophagus taurus: do alternative reproductive tactics favour alternative phenotypes? - Anim. Behav. 59: 459-466.

OKaDA Y. \& HaSEgaWA E. 2005: Size-dependent precopulatory behavior as mate-securing tactic in the Japanese stag beetle, Prosopocoilus inclinatus (Coleoptera: Lucanidae). - J. Ethol. 23: 99-102.

Parker G.A., Ball M.A., Stockley P. \& Gage M.J.G. 1997: Sperm competition games: a prospective analysis of risk assessment. - Proc. R. Soc. Lond. (B) 264: 1793-1802.

Pomfret J.C. \& Knell R.J. 2006: Sexual selection and horn allometry in the dung beetle Euoniticellus intermedius. - Anim. Behav. 71: 567-576.

RASMUSSEN J.L. 1994: The influence of horn and body size on the reproductive behavior of the horned rainbow scarab beetle Phanaeus difformis (Coleoptera: Scarabaeidae). - J. Insect Behav. 7: 67-82.

Rommel E. 1967: Ernährungsbiologie und Brutpflegeverhalten des kleinen Mondhornkäfers Copris lunaris (L.) (Col. Scarab.). Eine Vergleichsstudie zu den Arbeiten über den Spanischen Mondhornkäfers Copris lunaris (L.). - Nachr. Bl. Bayer Entomol. 16: 8-28.

Simmons J.L., Tomkins J.L. \& Hunt J. 1999: Sperm competition games played by dimorphic male beetles. - Proc. R. Soc. Lond. (B) 266: 145-150.

SivA-Jothy M.T. 1987: Mate securing tactics and the cost of fighting in the Japanese horned beetle, Allomyrina dichotoma. $-J$. Ethol. 5: 165-172.

Sugiura S., Yamaura Y. \& Makihara H. 2007: Sexual and male horn dimorphism in Copris ochus (Coleoptera: Scarabaeidae). -Zool. Sci. 24: 1082-1085.

Trillo P.A. 2008: Pre- and Post-Copulatory Sexual Selection in the Tortois Beetle Acromis sparsa (Cleoptera: Chrysomelidae). University of Montana, Missoula MT, $101 \mathrm{pp}$.

Received November 23, 2014; revised and accepted November 9, 2015 Published online February 15, 2016 